\title{
Challenges of loT deployment in the context of developing countries
}

\author{
Bernardo Y. León-Ávila [https://orcid.org/0000-0001-7985-0224], Yunior R. Hernández-Cabrera1, \\ Luis A. Quintero-Domínguez ${ }^{1}$ [https://orcid.org/0000-0002-3527-0516], \\ Felipe Hernández Pentón ${ }^{1}$, \\ and Frank R. Quesada Espinosa1 [https://orcid.org/0000-0002-1576-6733] \\ ${ }^{1}$ Universidad de Sancti Spíritus José Martí Pérez, Cuba
}

\begin{abstract}
The concept of the Internet of Things (loT) is not exactly a novelty, even if it has not burst out yet with all the force that the market expected. The 5th generation of mobile telephony $(5 G)$ is rushing to deploy in the midst of a real trade war, and intends to get one's own way on this and others fronts. This paper analyses how to overcome the challenges of an loT deployment, which can be too complex to fulfil its promise of massification and ubiquity. This analysis is primarily intended to identify whether $5 \mathrm{G}$ will be the key to a current loT deployment in all contexts, or whether it is wise to pursue other development paths first.
\end{abstract}

Keywords: 5G, loT, Road to Development

\section{Introduction}

Although all the current development of communication technologies has been oriented mainly to communication between people, new trends are encouraging machines and devices to connect massively, giving rise to Internet of Things (loT). The IoT represents an ecosystem that is expected to be made up of 100 billion devices by 2025: sensors, alarms, wearables, mobile phones, household appliances, code readers, etc. According to Huawei's estimations, on this date only $10 \%$ of the total connections will be between humans; the rest will be between devices in autonomous way.

Technologically speaking, when dealing with the loT there are three layers or levels. The first corresponds to devices, sensors and actuators whose main function is to capture different variables such as temperature or light, which are converted into electrical impulses (data). The second level is the "loT gateway" or gateway, which includes the hardware and software components that serve as a connection point between the cloud and the controllers, sensors and intelligent devices. This level 
configure the architecture required for data processing. Finally, the third layer of the IoT platform is where business, consumer applications and services are located [1]. The International Telecommunication Union (ITU) has created the overall roadmap for the development of $5 \mathrm{G}$ mobile technology and has defined the term "IMT-2020" to designate it. Following the completion of its work on the $5 \mathrm{G}$ "Vision" at the ITU Radiocommunication Section (ITU-R) 5D Working Party meeting in San Diego, California, the ITU defined the overall objectives, process and time frame for the development of $5 \mathrm{G}$ mobile systems [2].

To fulfil its promise of massification and ubiquity, loT requires an infrastructure deployment that industry has been unable to supply, and $5 \mathrm{G}$ promises to deliver. This paper attempts to analyze whether $5 \mathrm{G}$ will be the key to a current IO deployment in all contexts, or whether it is wise to pursue other development paths first.

\section{G for loT}

One of the strongest reasons to think about revolutionizing mobile telecommunications is the loT. The $5 \mathrm{G}$ is intended for this purpose, and its architecture has been redesigned by up to $36 \%$ to support the news requirements [3] In the words of Asha Keddy, general manager of mobile standards for advance tech at Intel, "we'll see computing capabilities getting fused with communications everywhere, so trillions of things like wearable devices don't have to worry about computing power because network can do any processing needed" [4].

The IHS Markit consulting firm has conducted a forecasting exercise through 2035 based on knowledge of the impact of previous generations of wireless technologies and forecasts of the enormous opportunities. One of their conclusion was that " $5 \mathrm{G}$ value chain will generate a return of $\$ 3.5$ trillion and 22 million jobs. This figure is larger than the value of today's entire mobile value chain" [5].

The basic performance criteria for $5 \mathrm{G}$ systems have been established by the ITU in its Recommendation IMT-2020. ITU-R M.2083 describes three general usage scenarios for $5 \mathrm{G}$ systems [6]:

- Enhanced Mobile Broadband, to cope with vastly increased data volumes, global data capacity and user density

- Massive machine type communications. This use case is characterized by a very large number of connected devices typically transmitting a relatively low volume of non-delay sensitive data. Devices are required to be low cost, and have a very long battery life

- Ultra-reliable and low latency communications to support mission-critical and safety-critical applications

At this definition stage, one might ask whether the work teams will make the standardization and regulatory decisions that make it feasible to meet these expectations.

Figure 1 shows the increase in $5 G$ network capabilities with respect to LTE-Advanced, technology for $4 \mathrm{G}$ by the 3GPP group. 


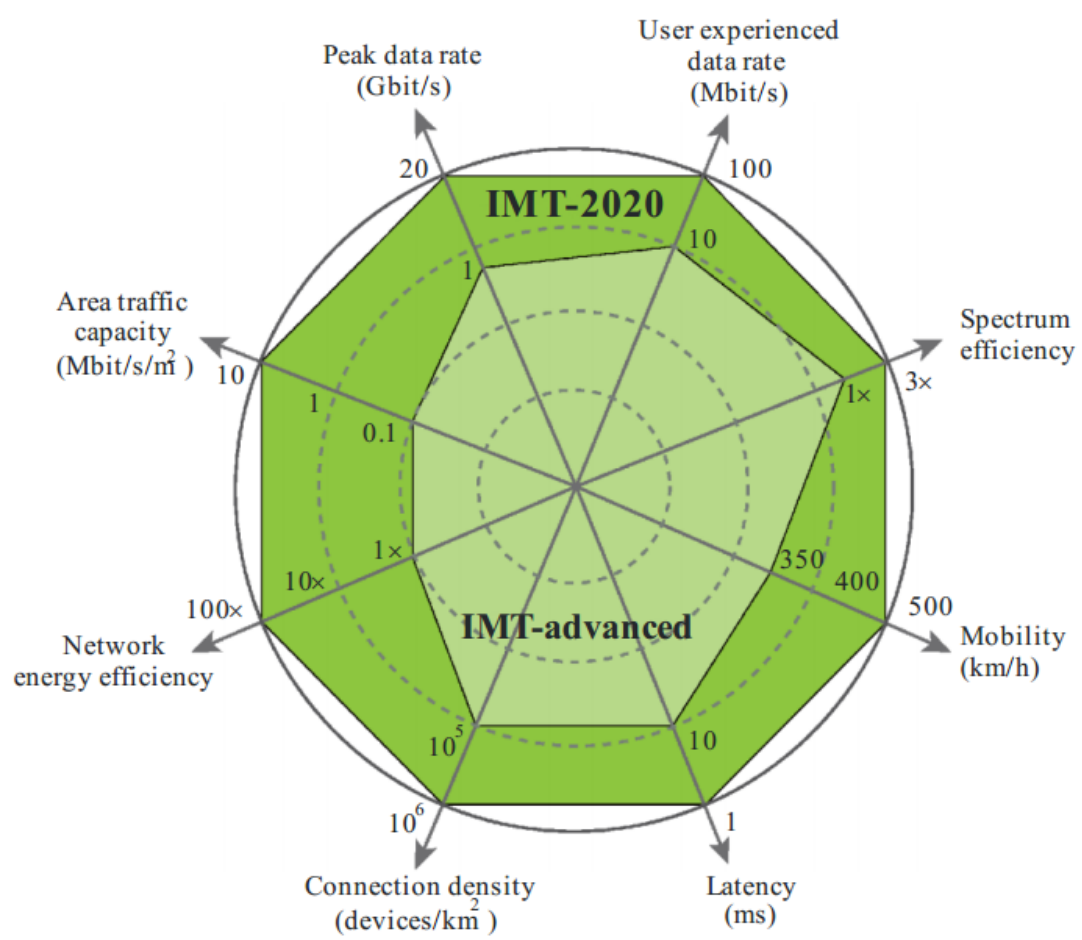

Figure 1. Enhancement of key capabilities from IMT-Advanced to IMT-2020 [6].

The 5G still has several major challenges to overcome that may slow down its massive deployment. The most illustrative are:

- The radio spectrum: This is probably the most important technological challenge facing $5 \mathrm{G}$ communications [7]. Brett Tarnutzer, director of the Spectrum GSMA, says "Operators urgently need more spectrum to deliver the endless array of services that $5 \mathrm{G}$ will enable (...) Without strong government support to allocate sufficient spectrum to next generation mobile services, it will be impossible to achieve the global scale that will make $5 \mathrm{G}$ affordable and accessible for everyone [7]. According with this goal, the GSMA has published the 5G Spectrum GSMA Public Policy Position [8].

In order to support all expected performance, the ITU proposes to use the frequency bands above $24 \mathrm{GHz}$ [8]. This means that operators will need to deploy thousands (or perhaps millions) of small cells throughout the territory: on streetlights and urban layouts, on the facades of buildings, and even inside individual homes, a deployment process that will be slow and require multi-million dollar investments.

- Security issue: More data means more challenges. Let's add that the $5 G$ is the first generation of mobile networks designed for M2M machine-to-machine communication. The biggest security challenge posed by $5 \mathrm{G}$ networks is privacy. $5 G$ networks will enable new types of applications and allow us to connect more 
devices to the network (and each other), encouraging us to capture and share more and more of our personal data. Some of which may never have been captured digitally before. In this regard, the 5G Americas group makes an analysis of the emerging threats facing $5 \mathrm{G}$ and the different mitigation mechanisms [9]. Threats that are not exactly new, but of a greater scope, so potentially more invasive and with catastrophic effects.

- Money Matters: All the promises of 5G will not exactly be painless for mobile ISPs. The $5 \mathrm{G}$ requires that the deployment of the networks responds to the ambition of those who have designed the new technology, multiplying several times the number of antennas and modifying their topology. The key is that, with $5 G$, ISP networks can be used for functions that are now impossible, significantly extending their range of use and therefore also increasing, at least theoretically, revenue. However, the high cost of deploying these new networks in all their magnitude is a great challenge especially for telecommunication operators who have to bear it, especially when the differential economic return, although intuited, isn't yet evident.

\section{IoT Deployments for Developing Countries}

$5 \mathrm{G}$ promises many technological advances and a great economic boost; but without a clear business model for all, and a prohibitive deployment cost for many economies. Maybe this new revolution in the field of mobile technology will have to wait for better times.

The biggest impact expected for $5 \mathrm{G}$ is on services and manufacturing. $5 \mathrm{G}$ 's main customers are machines and objects, so in economies with weak and obsolete industry, based on infrastructures with very poor or no automation, you will have very few customers to help you with ROI (Return on Investment). In the end, the funds for deployment will be taken from the development of other sectors that also need it, sectors whose activity will be reversed in development in a faster and more objective way.

So, if it is not wise to think about the deployment of $5 \mathrm{G}$ for now, it could be thought, do we have to postpone the loT as well? Of course not.

Although the 5G's sellers show it as the key piece for the massive deployment of the IoT, this concept has its own live, and has been born from several previous technologies and paradigms, so there are always excellent options.

\section{LPWAN}

LPWA (Low Power Wide Area) or LPWAN (Low Power Wide Area Network) for many authors. These terms do not denote any particular technology, but can be use as generic term to refer to any network designed perfom a low-power wireless communication with other networks, such as telephony, satellite communications or WiFi networks.

There are several technologies based on open or proprietary standards, such as LoRaWAN, Telensa, Sigfox, Igenu Networksentre's Random Phase Multiple Access (RPMA) and others. In a general sense LPWANs provide long range, promising 
coverage up to $15 \mathrm{Km}$ in open environments and up to $2 \mathrm{Km}$ in urban environments. They are designed to give access to a potentially high number of devices that have to transmit small amounts of data (few bytes) sporadically (e.g. every few minutes), mostly to the server.

LPWA networks are used almost exclusively in the field of loT devices and M2M communications. Its applications are in remote meter reading, public lighting control, theft alarms or control systems in infrastructure, crop irrigation system, unattended weather stations, animal control, and many others.

Another great advantage of these technologies is the use of unlicensed spectrum, although it is not in the classic $2.4 \mathrm{GHz}$ and $5 \mathrm{GHz}$. The chips typically offer channels in the 867 and $869 \mathrm{MHz}$ bands (Europe), 902 and $928 \mathrm{MHz}$ (America and Asia). The regulations on this subject should be reviewed for non-invasive use of licensed frequencies.

\section{NB-IoT}

Taking care your own network infrastructure, especially when there are nodes in the field, can be quite problematic for companies that don't want to have too large an IT structure. It would be desirable if our mobile provider have solutions that do not include the trauma of paying for a SIM card for hundreds of devices. The solution has been NarrowBand - Internet of Things or NB-loT for short.

The GSMA's initiative, NB-loT uses the mobile phone bands and is designed to operate in several ways, including the use of the GSM band replacing the current deployment (standalone). Also uses the LTE band and therefore sharing it (in-band), or even using the spacing between LTE channels to maximize the communications spectrum (guard-band).

NB-loT is a half-duplex technology that enables efficient uplink communication, that is, it allows the establishment of connection to the cellular network, the allocation of network resources to the node (known as User Equipment or UE) and the transmission of data (MT Data). In the most typically application, an UE will remain disconnected from the network and, when it has data to transmit, e.g. a meter reading, it will establish the connection, transmit the data and disconnect as soon as it receives confirmation of delivery [10].

NB-loT is reliable because it guarantees the data delivery. This is significant if is compare with other LPWAN technologies based on an ALOHA access. Also, the use of a licensed band makes it more reliable due it does not coexist with other technologies. However, using a licensed band has implications such as being dependent on an operator and therefore subject to a service and coverage model beyond control of the application. E. g. if LoRaWAN used, and there is little coverage, an extra Gateway can always be deployed; but with NB-loT, all is on the operator's hands.

\section{LLNs}

Like LPWA, LLNs (Low-power Lossy Network) is a set of technologies that include devices with very limited resources, both energy, computing performance and embedded memory. The main different with LPWA is the coverage area, just a few meters (around $200 \mathrm{~m}$ ). This networks are formed in multi-hop meshes to connect to 
the Internet. This idea follows the principle that multiple short jumps within a mesh are much more energy efficient than a single jump to a sink (gateway).

As in engineering, what is usually earned in one hand is sacrificed in the other. In an LLN, finding neighbors and then having them find a route to the gateway is not exactly a simple task. In LLNs, nodes (known as motes) must enter their work area, recognize their neighbors, and collaboratively find their way to the sink.

IEEE 802.15.4 is the standard for Low-Rate Wireless Personal Area Networks or simply Low-Rate Wireless Networks from 2015. The reduction of the acronym is due to the fact that its uses, potentialities and expectations began to go beyond the personal area to endorse the loT's lines.

An important step towards the robustness of these networks was the $802.15 .4 \mathrm{e}$ amendment [11] which specifies the TSCH (TimeSlotted Channel Hopping) mechanism within the multi-channel mechanism to mitigate the effects of multi-path fading and interference generated by different commercial devices.

\section{Conclusions}

For the first time, objects are the primary customer of a commercial telecommunications network. This is undoubtedly the most revolutionary contribution of the 5G, which expects to deploy the massive loT and applications with critical performance and delay requirements. Its gradual implementation of $5 \mathrm{G}$ will have an economic impact on all industrial sectors.

However, it should be keep in mind that any forecast will depend on the implementation timetable, national regulations and the possibility of consolidating the new business models. For now, its cost and deployment challenges are not justified in economies with a underdeveloped infrastructure that will presumably not exploit the capabilities and benefits of this new generation of mobile telephony.

But the loT is not intrinsically linked to $5 \mathrm{G}$. There are several solutions that can be deployed by both public operators and other companies that wish to expand their service portfolio using a more competitive model.

\section{References}

1 W. Dargie and C. Poellabauer, Fundamentals of Wireless Sensors Network, Theory and Practice. John Wiley and Sons, Ltd., 2010, ISBN: 978-0-470-99765-9.

2 ITU, ITU defines vision and roadmap for $5 \mathrm{G}$ mobile development, (accessed 2018-04-06), 2015. [Online]. Available:

http://www.itu.int/net/pressoffice/press_releases/2015/27.aspx (visited on 04/06/2018).

3 E. Obiodu and M. Giles, The $5 \mathrm{G}$ era: Age of boundless connectivity and intelligent automation, 2017. [Online]. Available: https://www .gsmaintelligence.com/ research/?file=0efdd9e7b6eb1c4ad9aa5d4c0c971e62\&download. 
$4 \mathrm{~K}$. Kaplan, The plans for $5 \mathrm{G}$ to power the internet of things, en, (accessed 2019-06-11), 2014. [Online]. Available: https://qz . com/179980/the-plansfor-5g-to-power-the-internet-of-things/ (visited on 06/11/2019).

5 K. Campbell, J. Diflfey, B. Flanagan, B. Morelli, B. O'Neil, and F. Sideco, The 5G economy: How $5 G$ technology will contribute to the global economy, (accessed 2020-06-11), 2017. [Online]. Available: https://cdn.ihs.com/www/pdf/IHSTechnology-5G-Economic-Impact-Study.pdf.

6 ITU-R, Recommendation ITU-R M.2083-0. IMT Vision - Framework and overall objectives of the future development of IMT for 2020 and beyond, (accessed 2020-04-21), 2015. [Online]. Available: https://www.itu.int/dms_pubrec/itur/rec/m/R-REC-M. 2083-0-201509-I! ! PDF-E.pdf.

7 A. Ilyas, 5G at Risk if Mobile Operators Don't Get Access to the Right Spectrum Newsroom, Oficial Web Site, (accessed 2020-02-11), Nov. 2018. [Online].

Available: https://www.gsma.com/newsroom/press-release/gsma-5g-atrisk-if-mobile-operators-dont-get-access-to-the-right-spectrum/ (visited on 05/20/2019).

8 GSMA Association, 5G Spectrum GSMA Public Policy Position, en-US, (accessed 2020-03-19), 2018. [Online]. Available:

https://www.gsma.com/latinamerica/resources/5g-spectrum-gsma-publicpolicy-position-2/ (visited on 03/19/2020).

9 5G Americas, The Evolution of Security in 5G, en-US, (accessed 2020-03-11), Jul. 2019. [Online]. Available:

https://www.5gamericas.org/the-evolution-of-security-in-5g-2/ (visited on 03/19/2020).

10 P. Tuset-Peiró, B. Martinez, and X. Vilajosana, Qué es NB-loT? es, (accessed 2019-06-13), Nov. 2018. [Online]. Available:

http://informatica.blogs.uoc.edu/2018/11/22/que-es-nb-iot/ (visited on 06/13/2019).

11 "IEEE Standard for Low-Rate Wireless Networks," IEEE Std 802.15.4-2015 (Revision of IEEE Std 802.15.4-2011), pp. 1-709, Apr. 2016. DOI:

10.1109/IEEESTD . 2016.7460875. 